\title{
IMPRENSA, INTELECTUAIS E EDUCAÇÃO: O BRASIL EM DEBATE NO SÉCULO XIX
}

\author{
Marcília Rosa Periotto \\ Universidade Estadual de Maringá
}

\section{RESUMO}

Este artigo é resultado de estudo sobre a imprensa, intelectuais e educação, tendo por fonte os jornais Correio Braziliense (1808-1822), de Hipólito da Costa e O Carapuceiro, de Miguel do Sacramento Lopes Gama (1832-1845). Os impressos são revisitados com o objetivo de comprovar a contribuição desta relação para o debate educacional na medida em que se compreende a educação como uma resposta para as questões de épocas históricas determinadas, no caso, o Brasil oitocentista. Na pesquisa com a imprensa do período, buscam-se marcar o caráter educativo dos debates políticos e os pontos de confluência entre esses jornais, expressivos de momentos distintos na história do Brasil, enfatizando-se a aspiração dos indivíduos que os compunham de orientar, instruir e mesmo cooptar a elite política e econômica para os embates de então. Para tanto, os dois exemplares da imprensa dos oitocentos pesquisados, redigidos por intelectuais, para os padrões do período, demonstram que a educação também se abriga em textos cuja finalidade seria assinalar as ações capazes de empreender as transformações necessárias à modernização do Brasil.

Palavras-chave: imprensa; intelectuais; educação; século XIX.

\section{THE PRESS, INTELLECTUALS AND EDUCATION: DEBATING $19^{\mathrm{TH}}$ CENTURY BRAZIL}

\author{
Marcília Rosa Periotto \\ Universidade Estadual de Maringá
}

\begin{abstract}
Results on studies with regard to the press, intellectuals and education, with special reference to the newspapers Correio Braziliense (1808-1822), published by Hipólito da Costa and $O$ Carapuceiro, published by Miguel do Sacramento Lopes Gama (1832-1845). Reviews on the above analyze the contribution of this relationship for the educational debate in so far as education is an answer to issues present in determined historical periods, or rather, $19^{\text {th }}$ century Brazil. Research on the printed matter of the period showed the educational characteristics of political debates and the confluence between the journals and newspapers which were salient moments in Brazil's history. In fact, they emphasized the participating individuals' aspirations to monitor, instruct and co-opt the political and economical elites for the debates. The two press samples from the $19^{\text {th }}$ century, published by intellectuals, show that education also lies in texts aiming on activities for the understanding of the necessary transformations in the modernization of Brazil.
\end{abstract}

Keywords: press; intellectuals; education; 19th century. 
Este estudo é sobre a imprensa brasileira no século XIX. Os jornais Correio Braziliense e $O$ Carapuceiro ${ }^{i}$ foram analisados com o objetivo de apontar as convergências entre o pensamento dos redatores, considerados intelectuais para os padrões da época, destacando-se o fato de que foram publicados em fases distintas da vida nacional no século XIX: chegada da família real, independência e regência. Em cada um observou-se a preocupação com a produção de condições efetivas de práticas materialmente progressistas como as da Europa. Da mesma maneira, os redatores elegiam a educação como uma das exigências para o almejado desenvolvimento material.

O significado de intelectual subsumido ao estudo compartilha, em parte, da posição de Gelbcke: "Assim julgamos como intelectuais aqueles personagens que se engajaram nas questões sociais e políticas, personagens que assumiram a missão de porta-vozes da população e que se doaram as causas que defendiam. (GELBCKE, 2001, p. 3).

Acrescenta-se a este entendimento a apreciação de que os jornalistas, ao se envolverem com os problemas postos pela dinâmica da sociedade burguesa de então agiram no sentido de responder às questões da época, produzindo ou transmitindo ideias, e ecoaram as transformações materiais exigentes de novos posicionamentos, inclusive, com a percepção de que suas intervenções na opinião dos leitores e governantes poderiam acarretar em mudanças sociais, ou mesmo a manutenção de interesses políticos expressivos dos grupos pretendentes do poder de mando político.

Assim, serão expostos e analisados os jornais na intenção de demonstrar aportes que exponham a similitude nos discursos quanto à visão de progresso econômico e social. A defesa de medidas afinadas com o desenvolvimento material e cientifico dominantes na Europa, a predicação por práticas econômicas de modelo burguês, inclusive o aconselhar a classe dirigente a extinguir a escravidão substituindo essa força de trabalho por imigrantes, tornou os jornalistas arautos das demandas capitalistas nos locais até então dominados pelos governos absolutos, vertidos em colonizadores. O debate de cunho político realizado por Hipólito, e o discurso moral e religioso de Lopes Gama, também atuando no campo da política, expressam a unidade no pensamento, embora os aspectos tratados por cada um sejam divergentes quanto à forma de exposição de ideias e aos temas abordados.

A questão principal do estudo gira em torno da concepção de progresso defendida por cada um dos redatores, da visão de educação presente nos seus escritos e das propostas voltadas à ascensão de uma nova nação rica e civilizada. Sobre as conexões existentes entre o pensamento desses jornalistas, ou intelectuais, pode-se adiantar que um dos nexos mais significativos é a compreensão que tiveram sobre a inexorabilidade do processo transformador imposto pelo capitalismo, cujos influxos advinham mais do mundo exterior do que mesmo das mudanças lentamente gestadas na sociedade.

Trata-se de um estudo sobre educação, vista no seu aspecto mais geral, subsumida aos debates sobre modernização e progresso, na necessidade de espalhar conhecimentos de toda ordem, desde as políticas afinadas com as práticas liberais até os conteúdos que fariam os governantes mais capazes no cuidado com as coisas públicas, adotando medidas eficientes para a promoção de melhorias nos territórios dominados.

Essa imprensa, em grande parte, soube captar as mudanças que exigiam novas posturas sociais e políticas e confirmou a vocação de ser um veículo interventor da vida pública e social. Junto ao caráter educativo que revestia suas ações forjou uma classe de intelectuais conectada aos problemas da época, ainda que muito deles representassem grupos sociais historicamente fadados ao desaparecimento, e deixou valiosas pistas sobre o processo transformador das relações no Brasil no século XIX. 


\section{A imprensa no contexto político-social do século XIX e a educação}

A inauguração da imprensa no Brasil desvendou uma característica intrínseca ao quadro precário da educação do povo brasileiro. Eram poucos os indivíduos que sabiam ler e escrever, um privilégio praticamente apenas ao alcance das elites que, quando podiam, enviavam seus filhos primogênitos ao estrangeiro para completar estudos, o que os levava, ao retornarem, a envolverem-se nas lides da imprensa, influenciados pelos ares de modernização respirados no continente europeu.

Esse panorama da instrução no Brasil marcava a dificuldade de encontrar indivíduos aptos ao cargo de redatores já que a rotina exigia colaboradores com significativo conhecimento das coisas do mundo, com capacidade de influenciar o público leitor e pressionar as estruturas sociais e de poder político. Por essa razão, entre outras, os "estrangeirados" predominavam na direção dos jornais, muitos deles tutelados por ilustrados portugueses, criando-se no Brasil o que Morel (2007) denominou de Repúblicas das Letras, expressa no $O$ Patriota, impresso de 1813 a 1814, sob os auspícios de d. Rodrigo Coutinho ${ }^{\text {ii }}$, um absolutista esclarecido, defensor de uma monarquia reformada, cujo projeto de cunho liberal visava modernizar o Império português. Luca (2012) lembra que:

É bom ter presente que, entre nós, as atividades ligadas à impressão datam da transferência da Família Real portuguesa, em 1808. Tal situação, aliada ao escravismo, escassa urbanização e diminuto público leitor, permite compreender porque o mundo das tipografias, com suas prensas, prelos, artistas do traço em suas diversas modalidades (xilogravura, talho doce, litografia) era um território dominado, em grande parte, por estrangeiros, observação igualmente válida para editores e livreiros. (LUCA, 2012, p.4).

Junto a essa particularidade havia também a preocupação de a imprensa, tradutora das ideias revolucionárias da época, insuflar o espírito de indivíduos dispostos a abalar os alicerces sociais. Havia o temor, manifesto em várias ocasiões em medidas do governo e nos discursos políticos e da própria imprensa, de que os ecos da Revolução Francesa penetrassem com maior rigor entre os descontentes com a administração portuguesa na colônia, a ponto de engrenarem uma revolta capaz de colocar em perigo o domínio ultramarino e finalizarem as relações entre a colônia e Portugal.

A existência da imprensa no Brasil se deve ao decreto real de 13 de maio de 1808, assinado por d. João na chegada da família real ao Rio de Janeiro. Após a liberação da palavra escrita, diversos impressos passaram a circular não só na corte como nas demais províncias, imbuídos da tarefa de divulgar os acontecimentos, circular ideias, informar sobre as matérias úteis para a agricultura, defender interesses dos grupos políticos, mas, também, gerar a possibilidade de uma forma de educação que, se não encontrava respaldo na administração pública, instruísse aquela parte da população carente de (in) formação acerca das novidades do mundo desenvolvido.

No século XIX, o debate pela educação no Brasil expressou a aspiração de parte das elites econômica e política de construir uma nova sociedade, com características mais aproximadas à modernização social da época. A imprensa tornou-se o meio de divulgação de ideias que traziam a preocupação central de civilizar os cidadãos, tornando-os propensos à reprodução do modo burguês, portanto habituados a rotina do trabalho. De acordo com Pallares-Burke, "a imprensa passa a ser constantemente referida como o meio 
mais poderoso e eficiente de influenciar os costumes e a moral pública, discutindo questões sociais e políticas" (PALLARES-BURKE, 1998, p. 147).

Neste sentido, tornou-se apropriado marcar a relação, mantida até os dias de hoje, entre imprensa e educação. A historiografia da educação, desde há duas décadas vem promovendo estudos sobre a imprensa dos oitocentos baseados nos periódicos, panfletos ou folhas publicadas muitas vezes com largo intervalo de tempo. Entretanto, de maneira geral, o que essa imprensa oferece aos pesquisadores da área, além do panorama ampliado das condições materiais e sociais do Brasil no período, é a memória do esforço de uma parte das elites em promover as condições adequadas a um estado laboral de igual qualidade ao europeu, notadamente ao da Inglaterra, e no qual a instrução do povo brasileiro era condição primeira.

A História da Educação se vê, portanto, representada pela agência de indivíduos dispostos ao esclarecimento dos povos, numa ação similar ao tempo das Luzes no velho mundo europeu. De certa maneira, o objetivo era o mesmo, extensivamente propalado nos editoriais que abriam os debates nos jornais. Se a educação, no sentido mais comum a ela atribuído, não chegava às províncias como atividade corriqueira e minuciosamente planejada, coube a imprensa o papel correspondente à Ilustração, capaz de modificar os homens ao apresentar outros modos de viver, novos hábitos e formas de pensar e produzir os bens materiais.

A função educativa desempenhada pela imprensa foi diligentemente captada pelo campo da historiografia educacional, e nos dias atuais vem apresentada numa série considerável de estudos nos quais as relações que compõem a vida geral de uma sociedade despontam como fatores cuja existência pleiteia um longo processo educativo, ao mesmo tempo em que deve conter a multiplicidade de interesses fundada pela época em questão. A importância da presença da imprensa nos estudos historiográficos traz o benefício de decifrar as imbricações entre a prática social e a teoria que a consubstanciava:

A análise da imprensa permite apreender discursos que articulam práticas e teorias, que se situam no nível macro do sistema, mas, também, no plano micro da experiência concreta, que exprimem desejos de futuro ao mesmo tempo que denunciam situações do presente (NOVOA, 2002, p. $11)$.

Além dos aspectos que alicerçam a utilização da imprensa oitocentista no âmbito das pesquisas em História da Educação, deve-se considerar o fato de que nela se registrou em pormenores o processo de constituição e consolidação da nação brasileira e, ao assim fazer, difundiu visões de mundo que se acreditava adequadas àquele construto. Agindo como veículo difusor de ideias e propósitos, a imprensa pautou o debate político e econômico e defendeu a necessidade da educação como eixo civilizatório. Na visão de Rocha (2205), os jornais

[...] caracterizam-se primeiramente pela difusão de informações, isto não significa que são neutros ou imparciais diante dos acontecimentos do cotidiano. E também por serem formadores de opinião pública, pelo fato de disseminarem análises a respeito do contexto político, educacional, comercial, religiosa entre outras. (ROCHA, 2005, p.3).

Ao mesmo tempo em que combateu pelo progresso, e em oposição a ele, a imprensa interferiu na constituição dos círculos de poder, foi contra e a favor da escravidão, propugnou pela modernização e pelo atraso, afinal, expressou as lutas incessantes entre os mais diversos interesses locais e sacralizou a tendência geral da época Revista HISTEDBR On-line, Campinas, $n^{\circ}$ 53, p. 41-55, out2013 - ISSN: 1676-2584 
de extinguir os resquícios do absolutismo e disseminar a civilização burguesa nos territórios recém libertos da colonização.

A pesquisa com a imprensa dos oitocentos oferece, então, não apenas a reconstituição analítica dos empreendimentos específicos a favor da educação, mas põe à luz os dilemas da sociedade brasileira a época, premidos entre propostas na qual o progresso era objetivo a ser atingido e as que privilegiavam a perpetuação do atraso. Esse embate, por sua vez, revela a ação de indivíduos comprometidos com projetos que buscavam pensar o Brasil e, que, pelo viés da imprensa, apostavam em criar uma consciência que refletisse as condições da época e se tornasse suscetível às mudanças necessárias a constituição da nação brasileira.

Entretanto, não se pode desconsiderar o fato de a imprensa não ser una nos seus propósitos, ao contrário, ela serviu a todos com diligência, muitas vezes agressiva, irônica, destrutiva, pois o que estava em questão era a luta por um projeto de nação no qual os progressistas e conservadores rejeitavam alianças em nome do poder que pretendiam tomar para si e, em outros momentos, capaz de persuadir com discursos acalentados na razão a opinião da massa e dos interesses em projeto.

O nascimento da imprensa no Brasil só foi possível em razão da necessidade da Coroa imprimir os decretos reais e outras matérias fundamentais à administração do reino. Não se deu de forma espontânea, tampouco expressou as demandas sociais do período porque até então na colônia brasileira era atividade proibida, ilegal, punível com aprisionamento dos autores, dos tipos, prensas e prelos. Para Meirelles,

Tal fato deu-se porque pela lógica do Antigo Regime não fazia sentido haver uma corte sem uma Gazeta, já que esta cumpria um importante papel na instituição monárquica: era, antes de tudo, um instrumento de afirmação da realeza perante todo o corpo social, uma vez que através da palavra o rei circularia sua imagem com toda plenitude para os seus súditos. A Gazeta do Rio de Janeiro, primeiro jornal institucional a circular por nossas terras era produzido pela Impressão Régia, que também tinha como função imprimir exclusivamente todos os papéis ministeriais e diplomáticos do real serviço, incluindo aí não só os documentos da Secretaria de Negócios Estrangeiros e da Guerra, mas de todas as outras repartições, além de imprimir as obras de particulares (MEIRELLES, 2007, p.2).

Estudos sobre esse primeiro jornal oficial ${ }^{\mathrm{iii}}$ brasileiro, criado para servir aos fins governamentais foram escritos sob diversos enfoques e esquadrinhado por temáticas também diferenciadas. José Carlos de Oliveira elaborou importante estudo sobre o papel da Gazeta na "constituição da cultura científica brasileira", resultante da preocupação de tornar o Reino mais competitivo frente ao avanço das nações progressistas:

Se era necessário estabelecer o Rio de Janeiro como sede do reino português, e deixar de considerar o Brasil uma mera colônia, era preciso a formação endógena de mão de obra capacitada para administrar o país e atender aos anseios pelo menos da elite aqui sediada, e dar continuidade aos interesses do governo português em jogo- dentro do contexto de iluminismo e reforma pombalina ainda influente. Essa formação de especialistas, em profissões que passam a desempenhar um papel central no mundo de comércio capitalista exigia a difusão de conhecimentos mais elaborados, divulgação de livros e manuais. (OLIVEIRA, 1997, p. 29). 
A necessidade de estimular o conhecimento científico denota a presença de intelectuais no comando dos órgãos de imprensa proliferados com a liberação real. Cercar o reino com as contexturas progressistas passou a ser vital para a continuidade do domínio lusitano sobre povos ultramarinos, além de permitir ombrear-se aos mais desenvolvidos. Era uma questão de sobrevivência, conjugada com o aumento das riquezas que se poderia obter com um maior e mais eficiente aproveitamento da prodigiosa natureza no Brasil.

Os intelectuais da Gazeta haviam nascido no interior da Ilustração portuguesa, formado suas ideias em meio à difícil transição entre o novo e o velho e presumiam um império progressista, desenvolvido, ilimitado nos ganhos econômicos, mas atrelado infinitamente ao poder absoluto. Hipólito da Costa compreendeu o anacronismo exalado pelas forças do passado e fez do Correio o porta-voz das forças do futuro, embora nem sempre tivesse expressado com o rigor do tempo histórico as necessidades do mundo colonial em travessia para a liberdade política. Já, Lopes Gama, n'O Carapuceiro, entendia que a civilidade necessária ao progresso repelia as condutas pessoais viciosas e hábitos cotidianos insensatos a um estágio social e material superior ao período colonial.

\section{O Correio Braziliense e a educação política da elite}

O jornal Correio Braziliense, publicado em Londres, comumente é designado pela historiografia como a mais significativa influência no processo de independência política. A ação que exerceu sobre os espíritos contribuiu para conduzir a luta contra o domínio português e aos prejuízos que a submissão àqueles interesses traziam aos negócios da elite econômica. A importância do pensamento e ação de Hipólito da Costa, marcados num jornal longevo para a época, são afirmados por Cinque (2010):

O pensamento de Hipólito da Costa, expresso no Correio assinalou um movimento decisivo para o Brasil, representado pelo processo que o retirou da condição de colônia e o fez país independente. A sua participação [...] revela o fato de que municiou a luta da elite brasileira contra a aristocracia portuguesa [...]. (CINQUE, 2010, p. 15-16).

Hipólito da Costa nasceu em Sacramento, no Rio Grande do Sul, no ano de 1774 e ainda adolescente foi enviado a Portugal para estudar. Nunca mais retornou ao Brasil, apesar de nunca tê-lo afastado do centro de suas preocupações. Morreu em 1823, logo após ser convidado a um posto no governo de Pedro I. A formação intelectual ${ }^{\mathrm{ivv}}$ se deu em Coimbra, onde se diplomou em Leis e Filosofia. Além desses cursos estudou outras matérias de seu interesse e talento, como informa Almeida (2004) em estudo sobre a condição do jornalista como pensador econômico:

A missão nos Estados Unidos buscava levantar os recursos naturais e apreciar os conhecimentos científicos que a jovem nação independente da América do Norte mobilizava em sua marcha ascensional para o progresso econômico. Hipólito estava habilitado para fazê-lo, uma vez que, ademais dos conhecimentos práticos aprendidos em sua vida de fazenda no Rio Grande, tinha sido formado em matérias como: filosofia, direito, botânica, agricultura, zoologia, mineralogia, física, química e mineralogia. (ALMEIDA, 2004, p. 2).

O interesse de Hipólito pelas ciências, acentuado na viagem que fez à Filadélfia em 1798, resultou num compromisso de vida feito em nome de projetos progressistas que, 
aplicados, contribuiriam para o aumento da riqueza do império português e no consequente desenvolvimento social da colônia brasileira. Oliveira assinala o vínculo entre ciência e produção burguesa na Europa, um quadro certamente benfazejo aos olhos de Hipólito a ponto de considerá-lo pertinente nos domínios lusitanos:

Na Europa, a ciência do século XIX já se tornara um importante apêndice para a produção. Ela se tornou um valioso auxiliar da produção, integrando-se com a técnica, principalmente nos países de capitalismo avançado. Nenhum governo de países pertencentes ao sistema capitalista e, portanto, desejosos de uma produção mais intensa, eficiente e lucrativa, poderia descartar os benefícios que o conhecimento científico poderia proporcionar a produção econômica. (OLIVEIRA, 1997, p. 30).

Aliado a essas questões de ordem econômica e científica, Hipólito patrocinou um debate tendo em vista orientar o governo português quanto a possíveis reformas na esfera de poder e na compleição de políticas progressistas, de cunho liberal. Concomitante a essa intenção, propôs-se a também participar da educação política das elites como uma forma de libertá-las das ideias apequenadas, aprisionadas a um tipo de vida não mais cabível para a sociedade burguesa mostrando, por meio de considerações políticas, filosóficas, culturais, circulantes na Europa e, ainda, amparado em exemplos factíveis, os caminhos que deveriam ser buscados nas reformas basais ao progresso geral da sociedade.

Como então alertar o governo e aos brasileiros sobre a conveniência das medidas necessárias à ampliação das possibilidades econômicas? Qual seria o seu ponto de partida? As pistas para descerrar o modo de operar de Hipólito são anunciadas já no editorial com o qual apresenta o Correio: "espalhar luzes" no objetivo de "mostrar, com evidência, os acontecimentos do presente, e desenvolver as sombras do futuro" (CORREIO BRAZILIENSE, 2001).

O propósito educativo com qual traçou a sua atuação contra as forças do passado ficava, pois, clarificado desde as primeiras linhas do Correio. A improdutiva administração colonial havia contribuído para esgarçar as relações entre portugueses e brasileiros, produzido um descontentamento geral alimentado pelo fato de que a elite econômica não encontrava espaço para agir no centro de poder, tampouco participar das decisões políticas que diziam respeito aos seus interesses. Essa evidência de esgotamento entre as partes já havia sido captada por Hipólito, da mesma maneira a sua opinião sobre o modelo colonial não deixava dúvidas que era hora de mudança, caso contrario a unidade do império português caminharia a passos céleres para o desaparecimento.

Cabia, pois, instruir as elites de Portugal e Brasil sobre as matérias mais pertinentes à anulação dos riscos de desagregação política e possivelmente territorial. Havia uma evidente rejeição das transformações mais gerais ocorridas na sociedade, estimuladas pelo medo das ideias revolucionárias de origem francesa, as quais poderiam influenciar o povo na luta pela emancipação política. Nesse período vigoravam ainda as proibições reais acerca da circulação de livros que confrontavam o absolutismo, só se lia os títulos franqueados pela Coroa, de conteúdo religioso, principalmente. Os estrangeiros eram vigiados e as bagagens revistadas à procura de qualquer escrito perigoso para a dominação portuguesa, além de uma população majoritária de analfabetos.

Esse quadro não era promissor a qualquer possibilidade de crescimento econômico e social, inclusive as determinações da Coroa atingiam, desde sempre, a própria elite, criada à revelia dos conteúdos civilizatórios, distante dos grandes centros em ebulição material. A tarefa era enorme, dificílima, os obstáculos quase intransponíveis, entretanto, o 
Correio não abnegou do propósito de instruir sobre os avanços materiais e sociais conquistados pelos europeus, querendo-os aplicados nos domínios portugueses.

A aristocracia portuguesa, alvo preferencial do jornal, na concepção de Hipólito, era a causadora dos desarranjos comerciais e econômicos do reino. Cuidava, então, de diuturnamente alertar aos brasileiros e portugueses insatisfeitos sobre a inoperância dessa classe, criticando asperamente a incapacidade que demonstravam no cuidado com os negócios: "É característica da ignorância, a obstinação e presunção; e a estas fraquezas atribuímos nós os males que os Ministros Portugueses causaram ao comércio de sua nação, com tais estipulações" (CORREIO BRAZILIENSE, 2001, vol. VI, p. 228-240).

Revelar a origem dos males, que assombravam a elite econômica, e demonstrar os caminhos acessíveis ao desenvolvimento exigia um projeto detalhado do que fazer, dos rumos seguir e quais os expedientes capazes de influir positivamente nas vontades e decisões governamentais. A solução estava em dar a conhecer o cabedal das transformações burguesas e incitar o desejo de vê-las em expansão nos domínios portugueses arregimentando, para isso, forças sociais em gestação.

No artigo Necessidade de reforma no governo do Brasil (junho de 1811), expõe propostas para o engrandecimento do Brasil solicitando a remoção dos obstáculos que o impediam de crescer. O primeiro ato seria "reformar os abusos", perpetrados pelos ministros, "homens malvados, que cobrindo seus crimes com a autoridade do Príncipe, o fazem odiosos à nação" (CORREIO BRAZILIENSE, 2001, vol. VI, p. 566-573, maio de 1811), seguido do afastamento desses indivíduos dos postos ocupados na administração do reino por considerá-los inaptos à governança por ausência de conhecimentos específicos das pastas que ocupavam, e traidores, pois, ao aconselharem o monarca o faziam em vista da preservação dos seus interesses. Outro ponto fundamental era o estabelecimento de uma monarquia constitucional, com limites ao poder do monarca, o que seria uma das formas indicadas para conter os excessos da nobreza, significando tirar dela o usufruto do poder.

O segundo momento seria permitir a liberdade de imprensa, com a circulação de jornais ${ }^{\mathrm{vi}}$ que não dispensavam atacar as arbitrariedades dos governantes e sugerir reformas profundas no círculo do poder: "conservam a imprensa escrava em Portugal e no Brasil; para que ninguém, de viva voz ou por escrito, se atreva a dizer nada dos semideuses que governam" (CORREIO BRAZILIENSE. 2001, vol. VI, p. 566-573, maio de 1811).

Franquear a ação da imprensa resolveria as conseqüências maléficas das rebeliões populares acalentadas pela insensatez ou insufladas por aventureiros, dizia Hipólito. O mais conveniente a um estado de bem aventurança política e econômica seria, por intermédio da imprensa, esclarecer as elites sobre as vantagens do progresso, da oportunidade de reformas que alterassem em definitivo o quadro de poder, afastando-se os indivíduos insuficientes em termos de sabedoria no encargo de administrar o reino. Para isso era urgente a propagação das ideias sustentadoras da pujança inglesa- o liberalismo-, a defesa do livre comércio, bem como o alerta sobre a imprudência dos tratados comerciais com os ingleses sem que se tivesse objetivamente claro os pontos mais favoráveis ao Brasil e menos à Inglaterra.

Liberal, Hipólito entendia que o poder econômico e material de uma nação se construía sob os ditames do trabalho livre e da aplicação crescente da ciência e da técnica nas atividades produtivas e laborais. Neste sentido abolir a escravidão, lenta e gradual, substituindo escravos por colonos vindos do estrangeiro seria medida bem sucedida, pois as nações em desenvolvimento, como nos Estados Unidos, por exemplo, passaram a adotar o procedimento, conseguindo com isso bons resultados no projeto colonizador.

Dessa maneira, uma forma livre de governo, com liberdade ao comércio nativo, sem interferência da Inglaterra e dos privilégios portugueses seriam decisivos na 
implantação de práticas progressistas. A experiência obtida na prática de negociar e o estudo atilado das matérias necessárias dariam ao Brasil as vantagens do conhecimento e perspicácia no momento de decidir os tratados comerciais benéficos aos interesses pátrios. Por outro lado, o plano de melhoramentos continuaria se o governo consentisse o acolhimento dos europeus "que se refugiam da opressão dos seus inimigos" garantindolhes "que a propriedade e liberdade pessoal dos indivíduos seja respeitada, em conseqüência de leis fixas e permanentes" (CORREIO BRAZILIENSE, 2001, vol. V, p. 652-654, dezembro de 2010).

Os problemas levantados por Hipólito da Costa, as soluções apresentadas aos governantes sobre como modificar as práticas políticas perniciosas ao desenvolvimento material do reino e aos indivíduos dispostos a empreender conquistas materiais de vulto, a partir da aquisição dos conhecimentos fundamentais à produção, permanecem no Correio Braziliense à espera de novos estudos.

Desta maneira, sobressai no conjunto da obra escrita por Hipólito a capacidade intelectual que desfrutou ao longo de sua vida e expôs com critério no Correio, além dos objetivos clarificados em contribuir para o desenvolvimento do império português, num primeiro momento e, num segundo, pela grandeza do Brasil. Sobre esse aspecto pode-se argumentar que o conceito de intelectual voltado aos problemas sociais, coadjuvado por um infinito conhecimento sobre as mais diversas áreas cabe como uma luva ao jornalista, e onde se ressalta ainda a agudeza de percepção de que educar sobre os temas mais pertinentes ao governo das nações industriosas constituía-se na condição civilizatória requerida pelo grau de desenvolvimento social da sua época.

\section{O Carapuceiro e a educação religiosa e moral}

Padre Miguel do Sacramento Lopes Gama nasceu em Recife no ano de 1791 e faleceu em 1852. Seu jornal, inaugurado no dia 7 de abril de 1832, período regencial, caracterizou-se por ser um órgão de imprensa de cunho moralista frente às forças sociais em transformação. $O$ Carapuceiro, um jornal satírico e de crítica do cotidiano provincial trazia, entre outros objetivos, influenciar o meio social no sentido de enfrentar os danos do incipiente progresso que chegava ao Brasil. Entretanto, $O$ Carapuceiro não fazia prelação contra o progresso material, mas incomodavam-lhe as consequências "nefastas" de sua aplicação por não estarem os brasileiros suficientemente preparados na assimilação das novidades advindas com as novas práticas sociais.

$\mathrm{Na}$ busca por convergências entre o pensamento de Hipólito e Lopes Gama, o estudo se atém a dois aspectos capitais ao conteúdo do jornal: progresso e arcaísmo, os quais, por sua vez, estão imbricados no acirrado debate arrostado pela elite política e econômica e por intelectuais no processo de elaboração do projeto de nação no decorrer do século XIX, e que impôs ao Brasil uma concepção elitista de Estado em vigor até os dias de hoje.

Lopes Gama, fundador e único redator do jornal O Carapuceiro, expressou essas ambivalências ao atuar na política, educação e vida religiosa. A ação educativa pertinente ao jornal esteve além da informação na medida em que fomentou ideias e criticou ações que deslustravam o modo de vida adequada ao modelo conservador e patriarcal de nação que se construía.

O caráter educativo do jornal tem duplo sentido: o primeiro se refere ao aspecto geral da educação, isto é, o esforço realizado para produzir os homens necessários à época histórica em questão, e, o segundo expressa a disposição constante de educar, instruir e 
dirigir as condutas tendo em vista cumprir o projeto de nação delineado pelas elites política e econômica.

Os desafios enfrentados por Lopes Gama ganham vigor quando se os consideram muito aproximados e até desdobramentos de uma época histórica indecisa entre o velho mundo que ruíra com a separação de Portugal e o novo mundo descortinado com a abertura dos portos aos estrangeiros e da independência política, que permitiu aos brasileiros uma liberdade antes não experimentada e tida por inconquistável durante muito tempo.

Em termos das relações internas os embates entre os poderes locais e os travados no âmbito do poder central se inclinavam por modelos diferenciados de Estado, centralizador ou não, desenvolvimentista ou reformador, avanço ou regresso, etc., todavia, prevaleceu o consenso pela unidade imperial, fato de maior importância para a elite consagrada ao setor agroexportador, e a possibilidade de coesão da ordem social vigente.

A época de Lopes Gama se inclui no quadro de profundas transformações, impelindo-o tratar da moral como remédio para os excessos da sociedade, expressando a questão que a sobressaltava: progresso ou arcaísmo? A resposta, entretanto, não podia ser encontrada nos acontecimentos apenas, mas na relação entre eles e os indivíduos, entre homens e a história. A história brasileira no século XIX, no seu decorrer, foi também de construção, primeiramente de ideias que iriam dar substância às ações da elite, e, segundo, da ideia de uma nação civilizada e progressista como as européias. A questão maior, entretanto, que aflora nos escritos do padre Carapuceiro é o embate entre as forças conservadoras egressas da submissão aos poderes metropolitanos e a modernidade decorrente da penetração burguesa nas recém libertas colônias.

Estes aspectos embasariam o debate intelectual e político sobre o modelo de nação e, ao mesmo tempo de Estado, que se construía alicerçado nas demandas da classe dominante, existindo por e para ela. A Igreja contribuiu produzindo e sedimentando a vida cotidiana e pessoal nos limites da moral e da religiosidade exacerbada. Lopes Gama, formado no interior da Igreja, foi pródigo nessa tarefa, construiu, difundiu e cobrou dos indivíduos uma conduta regrada pela prática incontestável dos preceitos religiosos, fazendo dessa ação uma estratégia política que buscava beneficiar a própria Igreja, mas que também lhe servia no trato das questões comuns as quais desempenhava na condição de deputado provincial, membro da Assembléia Nacional no Rio de Janeiro.

Os termos com os quais procurou afirmar os passos necessários a uma educação calcada nas Sagradas Escrituras aparecem vinculados às questões da época na perspectiva da transformação social, já que o progresso social levava às nações adiantadas alterações demasiadamente profundas na vida social, produzindo comportamentos individuais excêntricos aos costumes, repetidos por gerações, mas, nos tempos modernos, rechaçados como inadequados à nova realidade.

Moderno, modernidade e modernização são termos que passariam a partilhar as preocupações dos homens do século XIX brasileiro. Cada um dos envolvidos nessa construção, intelectuais ou membros da elite agrária, compreenderiam o processo com os limites teóricos particulares, e de certa forma desejavam a inserção naquelas condições de acordo com os interesses que tinham de defender, já que os interesses, num primeiro momento, são os próprios ou dos grupos aos quais se aliam.

Modernizar, portanto, seria construir-se classe dominante e elite circundante ao poder imperial. A construção do Estado imperial seria o objetivo fundamental daqueles indivíduos, premidos, inicialmente, pelos embates regionais e compromissos arrostados localmente, mas partidários da luta em nome da unidade do território em contraposição à ideia de autonomia provincial que abalou, em diversos momentos, o império brasileiro. Centralização era a palavra de ordem e a sua efetividade dependia de um ideário comum 
aos brasileiros, cujos princípios seriam modelados no barro das práticas morais virtuosas, leiam-se, interesses de classe, representativos da elite que buscava criar um Estado nacional à sua semelhança.

O Carapuceiro foi um porta-voz dessas aspirações: centralização e dissociação entre a administração do Estado com os interesses portugueses, os quais insistiam em manter seus tentáculos fincados na estrutura do Estado imperial. Ao mesmo tempo, combateu em nome dos interesses da Igreja, alijada, em grande parte, da estrutura e do exercício reconhecidamente anexo ao poder. O debate moral constituiu-se uma arma, manejada com o objetivo de construir ideologicamente um tipo de pensamento propenso ao reconhecimento da superioridade da elite na condução da nação, pedagógico e modelador das virtudes as quais os cidadãos, ricos ou pobres, deveriam perseguir na vida privada.

O debate moral, de cunho religioso, destinava-se mais a erigir o edifício social nas bases necessárias ao novo Estado do que a manutenção dos fiéis apresados aos preceitos religiosos, aliás, eram esses os artifícios manejados na busca da civilidade no momento de sedimentar os meios que dariam sustentação às ações de seus agentes. Entretanto, Lopes Gama, pontuava o afastamento das obrigações cristãs como fruto do "racionalismo" que "estava penetrando insidiosamente em todos os setores da vida pública e privada, inclusive dominando a situação filosófica e religiosa do período, fazendo arrefecer a fé das pessoas nas doutrinas e nos dogmas cristãos" (VITORINO, 2002, p. 68).

A empresa assumida n'O Carapuceiro no sentido de moldar as consciências, para Lara se expõe na seguinte questão: "que sentido ou que profundidade dar à revolução que se operava no Brasil: tratava-se de formar uma sociedade em bases novas, ou tratava-se de organizar um novo Estado para uma sociedade antiga que, agora, conseguia a sua autonomia política? (LARA, 1988, p.18). Estas indagações acompanhariam o jornal durante a longeva publicação dos seus escritos, e de certa forma conduziram o combate travado por Lopes Gama primeiramente com as inconstâncias de sua época e depois com as suas próprias, definidas entre ser progresso ou ser arcaísmo.

Ao compreender a necessidade e a urgência de promover uma regeneração moral com vistas à política futura, o jornal $O$ Carapuceiro (1832-1845) deixava de ser apenas um órgão de na crítica dos costumes. $O$ caráter educativo presente no jornal equivale às estratégias adotadas na educação dos brasileiros em busca da civilidade superior que acreditava dignificar a nação que se construía e esteve adiante nas primeiras intenções que deram vida ao seu jornal.

A educação, idealizada por Lopes Gama, buscava instruir os filhos da elite, os futuros governantes, primeiro como homens de bem, naquilo que Challandes (2003) entendeu como aspiração em Diogo Antonio Feijó, o homem moral, que "é aquele que compreendeu ser seu dever aspirar à justiça antes de buscar seu bem-estar pessoal; aquele que usa sua liberdade, sua razão e seu sentido moral para perceber a ordem" (CHALLANDES, 2003, p. 23).

Se a questão era construir a nação, também era tempo de erigir o modelo de homem adequado aos negócios públicos, um tipo de homem que se dispusesse, mesmo em prejuízo próprio, encimar os desígnios sociais, portanto, afeito a "obedecer aos superiores", a não confundir liberdade com "insubordinação e anarquia" (CARAPUCEIRO, 1838, n 20).

A justificativa de uma educação sóbria e circunscrita se apoiava na máxima "Nem tudo é para todos, nem todos são para tudo", que colocava cada componente do espectro social no lugar ocupado por cada um, em particular, devendo, portanto a educação, ser conduzida afastando os pendores naturais da espécie humana e os substituindo gradualmente com a madura civilidade. 
Essa era uma das razões por qual condenava os estrangeirismos que infestavam os ensinamentos, a gramática incorreta, as novelas consideradas "uma peste, são venenos que em vasos de ouro de propinam à mocidade", o contato e a influência desmedida da escravaria na instrução dos meninos, todos vistos como óbices ao engrandecimento da nação e, principalmente, provocavam a indiferença religiosa nas classes elevadas. Essas condições eram prejudiciais a construção do caráter, vital ao futuro político, que deveria, quando adulto, renunciar aos prazeres individuais sufocando as vontades próprias e construindo uma existência moldada nas virtudes e na observância dos princípios morais.

Lopes Gama e o jornal $O$ Carapuceiro constituem figuras importantes para a História da Educação, escrita na perspectiva das relações político-educativas, ou seja, no processo de construção de uma sociedade organizada, civilizada, e na qual vigorasse a moralidade na condução da vida pública. O homem público que emerge dos seus escritos situa-se entre pólos opostos traçados por um lado pelos conservadores adeptos da centralidade e da hierarquização no exercício do poder, e do outro pelos liberais, também afetos à ordem, mas partidários da descentralização do poder e de maior autonomia provincial, cujo desempenho ficaria ao encargo dos grupos políticos locais.

\section{Conclusão}

Apontar as similitudes entre o Correio Braziliense, de Hipólito da Costa e O Carapuceiro, de Lopes Gama resulta numa análise que permite visualizar a forma como as questões do início do século XIX, agregadas ao Brasil, foram absorvidas por parte da intelectualidade do período. Os debates subseqüentes ao desenvolvimento material da colônia, primeiramente, e já na condição de território liberto da dominação portuguesa, num segundo momento, foram expressivos das transformações mundiais que chegavam ao Brasil criando novas demandas na rudimentar sociedade local.

É preciso, porém, estar atento ao intervalo de tempo, curto, mas decisivo, que separa o debate nos dois jornais, como também aos fatos histórico, pontuais, que ambos enfrentaram. Nas duas décadas iniciais do século XIX o Brasil carregava o fardo de permanecer submetido à Coroa portuguesa e a elite econômica sem autonomia para cuidar dos próprios negócios. No início da terceira década o Brasil viu Pedro I voltar a Portugal, o espocar de rebeliões, a luta entre os liberais e regressistas e as regências.

Hipólito da Costa, no horizonte das suas ponderações compreendia esse quadro político, sistematicamente alimentado pelo desinteresse da aristocracia em tornar a colônia portuguesa mais abastada num campo fértil de riqueza materialmente produzida. As reiteradas negativas do governo absoluto quanto a implantarem-se reformas úteis ao desenvolvimento talvez seja ilustrativo de um sentimento intuído, mas não aclarado, de que nelas encontravam-se os indicativos da ruína da nobreza portuguesa, acompanhando o movimento histórico em favor da burguesia.

Lopes Gama, por sua vez, iniciou a atuação como jornalista no período regencial, em 1832, logo após Pedro I abdicar e retornar a Portugal, ficando o Brasil sob o comando de regentes com a atribuição de manter o sistema imperial e a preservação da figura do futuro imperador até que alcançasse a maioridade. Nessa década de atribulações políticas e sociais, que se findou nos lances dramáticos da Maioridade, o Brasil conheceu um tempo de conflitos e sedições encabeçado por setores da elite que atuavam no propósito de diminuir a presença portuguesa nas lides da política e dos privilégios que se mantinham ainda preservados, além de garantir a unidade territorial ameaçada pelas províncias descontentes com a centralização do poder na corte imperial. 
Entretanto, se o tempo de Hipólito transitou entre o ser colônia e a luta pela independência até vê-la conquistada, e o de Lopes Gama situou-se na difícil década de construção de caminhos possíveis à sedimentação de uma ideia de nação, bem como ao recrudescimento da luta entre liberais e conservadores que se arrastou até fins da década de 40 dos oitocentos, na rebelião Praieira, numa Recife exposta aos interesses dos mandos locais. Essas diferenças nos tempos históricos levam à consideração de que o pano de fundo das suas ações foi o denominador comum, representado pelas práticas políticas reticentes ao progresso do Brasil e as quais se deveriam abater.

Enquanto que para Hipólito os prejuízos na adoção de projetos econômicos de cunho liberalizantes emanavam do quadro das políticas absolutistas, onde rei e nobreza exerciam o poder sem que se admitissem contestações a ele, para Lopes Gama, o progresso, tão necessário ao engrandecimento da recém-nação, poderia pô-la a perder caso se normatizassem as práticas cotidianas chamuscadas pelo que de pior traziam as novidades estrangeiras, como os hábitos que via nocivos à formação da juventude.

O projeto civilizador que sobressai dos escritos de Hipólito pode contar com o beneplácito advindo da presença dos monarcas e da corte, criando o ambiente necessário para a elite nativa almejar situar-se no mesmo patamar de civilidade, portanto não mais afeita ao papel de coadjuvante. Já em Lopes Gama, percebe-se o intelectual forjado nos limites da vida colonial e alçado, num curto espaço de tempo, a um processo de transformações que desfiguravam as velhas tradições e colocavam em dúvida os pilares nos quais a sociedade havia assentado as suas práticas cotidianas. Pressentia ai o perigo, na admissão de costumes abaulados no frenesi do progresso, da contestação pelos mais jovens do poder pátrio no âmbito familiar, no desmerecimento que via acometer a opinião das pessoas a respeito da religião como condutora espiritual e moral das suas vidas.

Educar passava, então, a ser o ponto nodal nos discursos desses intelectuais. Logo após a independência, Hipólito reconhecia o novo tempo- "Agora é o tempo de começar"$\mathrm{e}$ as dificuldades a serem enfrentadas, entretanto, confiava no poder das Luzes, na educação promotora dos conhecimentos necessários a um governo adepto da liberdade e do progresso. Lopes Gama, por seu lado, defendia a Ordem, calcada nos ensinamentos morais, visando o bem comum, cuidado com desvelo pelos indivíduos que, formados sob os ditames dos princípios cristãos, estariam capacitados para governar a sociedade em geral. $\mathrm{Na}$ sua visão, a moral não se reduzia aos comportamentos inadequados, na concupiscência dos costumes individuais, mas a apontava como um elo na unidade necessária à construção da sociedade brasileira, no qual a probidade política seria, então, extensão da integridade de princípios e de ação individual, tendo o Estado como receptor e agente dessas virtudes.

Hipólito da Costa e Lopes Gama se apresentam como interpretes de uma época histórica cujas lições apontavam para a modernização social. Ambos conferiam à educação uma intencionalidade cuja expressão maior era estabelecer as condições políticointelectuais, em Hipólito, e as condições morais objetivadas ao império da ordem, em Lopes Gama, visando construir uma sociedade progressista, politicamente aderida ao bem comum, favorável ao trabalho livre, apta ao desenvolvimento das ciências, refratária à anarquia social e moral, portanto, civilizada. 


\section{Referências}

ALMEIDA, Paulo Roberto de. O intelectual Hipólito José da Costa como pensador econômico. IN: Intérpretes do Brasil: cultura e identidade. Gunter Axt e Fernando Schüller (orgs.). Porto Alegre, RS: Artes e Ofícios, 2004, p. 49-61.

CASTANHA, André Paulo Castanha. Moralidade Pública e Educação no Século XIX. IV Congresso Brasileiro de História da Educação, 2006, Goiânia. Anais do IV Congresso Brasileiro de História da Educação. Goiânia: Editora da UCG, 2006. v. 1. p. 1.

CHALLANDES, Jean Philippe. As bases morais da nação e do patriotismo no pensamento político de Diogo Antônio Feijó e seus aliados (1819-1839). TEXTOS DE HISTÓRIA, vol. 11, ns 1/2, 2003, p. 63.

CINQUE, Fernanda Regina. A ação educativa do jornal Correio Braziliense e a História da Educação. IN: Império em debate: imprensa e educação no Brasil oitocentista. Celina Midori Murasse Mizuta, Luciano Mendes de Faria Filho, Marcília Rosa Periotto (orgs.). Maringá/PR: EDUEM, 2010.

CORREIO BRAZILIENSE OU ARMAZÉM LITERÁRIO. São Paulo: Imprensa Oficial do Estado; Brasília, DF: Correio Braziliense, 2001-2003. Edição fac-similar. Encadernado em 31 volumes.

GELBCKE, Vanessa Raianna. A educação, imprensa e intelectuais: um estudo dos periódicos Gazeta do Povo e Diário da Tarde (1910-1930). X Congresso Nacional de Educação- EDUCERE. I Seminário Internacional de Representações Sociais, Subjetividade e Educação- SIRSSE. PUC-PR, Curitiba, 07 a 10 de novembro, 2011.

LARA, Tiago Adão. Tradicionalismo Católico em Pernambuco. Recife: FUNDAJ; Editora Massangana, 1988.

LUCA, Tania Regina de. A Ilustração (1884-1892): algumas questões teóricometodológicas. Colóquio: A circulação transatlântica dos impressos. Conexões. Agosto de 2012. ECA/USP.

MEIRELLES, Juliana Gesuelli. A Gazeta do Rio de Janeiro: o jornal oficial da Corte de D. João VI no Brasil (1808-1821). Intercom - Sociedade Brasileira de Estudos Interdisciplinares da Comunicação V Congresso Nacional de História da Mídia - São Paulo - 31 maio a 02 de junho de 2007.

MOREL, Marco. Pátrias Polissêmicas: República das Letras e imprensa na crise do Império português na América. IN: Iluminismo e Império no Brasil: O Patriota (18131814). KURY, Lorelai (org.). Rio de Janeiro: Editora Fiocruz, 2007.

NASCIMENTO, Luis. Apresentação. IN: O Carapuceiro. Recife: Fundação de Cultura Cidade do Recife, 1983. vol. 1.

NÓVOA, António. A imprensa de Educação e Ensino: concepção e organização do repertório português. IN: CATANI, Denice B.; BASTOS, M. Helena C. (orgs.). Educação em Revista: a imprensa periódica e a História da Educação, São Paulo: Escrituras, 2002, p.

O CARAPUCEIRO. Miguel do Sacramento Lopes Gama, 1791-1852. Recife: Fundação de Cultura Cidade do Recife, 1983. 3v.

OLIVEIRA, José Carlos. A Cultura Científica e a Gazeta do Rio de Janeiro (18081821). Revista da Sociedade Brasileira de História da Ciência, n. 17, p. 29-58, 1997. 
PALLARES-BURKE, Maria Lúcia G. A imprensa como uma empresa educativa no século XIX. Caderno de Pesquisa, n.104, p. 144-163, jul. 1998.

ROCHA, Rita de C. L. Imprensa, Educação e Civilidade. IX Simpósio Internacional Processo Civilizador. Ponta Grossa/PR, novembro, 2005.

VITORINO, Artur J R. Leitores e leituras de romances franceses em nossas plagas imperiais. Cadernos AEL, vol. 9, n. 16/17, 2002, p. 59-92. ael.ifch.unicamp.br. Acesso: 22.01.2014.

\section{Notas}

1. Os jornais Correio Braziliense e O Carapuceiro, publicados no século XIX, compõem o rol de órgãos de imprensa que tem sido pesquisados e analisados pela autora, com apresentação dos resultados em eventos da área e ou publicados na forma de artigos. Atualmente pesquisa a temática "educação da mulher" no corpo do jornal $O$ Carapuceiro. O estudo está ligado ao projeto Moderno, Modernização, Modernidade: a educação nos projetos de Brasil nos séculos XIX e XX, CNPq, UFMG, coordenado pelo professor Luciano Mendes de Faria Filho.

${ }^{2}$. D. Rodrigo de Souza Coutinho, Conde de Linhares, de tendência liberal, ligado ao Marquês de Pombal, foi um dos maiores representantes da Ilustração portuguesa do período, um grande auxiliar da Coroa e um dos mais influentes políticos da sua geração. Nasceu em 1755 e faleceu em 1812.

3. A Gazeta do Rio de Janeiro contou com colaboradores esclarecidos, oriundos da esfera governamental e censores das matérias que trariam prejuízos aos interesses da Coroa. Meirelles assinala que "A primeira Junta Diretora do jornal foi composta por 3 homens ilustrados de estrita confiança de D. João VI. José Bernardes de Castro, além de diretor da Impressão Régia durante o período joanino, foi deputado das mesas de inspeção do Rio de Janeiro e da Bahia e colaborador d'O Patriota; primeira revista literária fundada no Rio de Janeiro por Manoel Ferreira de Araújo Guimarães, em 1813. Marianno José Pereira da Fonseca, bacharel formado em matemática e filosofia pela Universidade de Coimbra, serviu na Junta do Comércio, foi administrador tesoureiro da fabrica de pólvora, e censor régio. (Também foi senador do Império e, em 1821, foi eleito deputado da Junta Provisória criada no Rio de Janeiro, em meio à resolução das Cortes). [...] José da Silva Lisboa, futuro visconde de Cairu, era bacharel em direito canônico e filosófico. Especialista em retórica exerceu a cadeira de Filosofia Racional e Moral da Bahia por mais de vinte anos. Entre 1808 e 1821, foi professor de economia política, deputado da Junta do Comércio, desembargador da Relação da Bahia e também censor régio. (MEIRELLES, Juliana Gesuelli. A Gazeta do Rio de Janeiro: o jornal oficial da Corte de D. João VI no Brasil (1808-1821). Intercom - Sociedade Brasileira de Estudos Interdisciplinares da Comunicação V Congresso Nacional de História da Mídia - São Paulo - 31 maio a 02 de junho de 2007.

${ }^{4}$. Hoje são muitos os estudos elaborados sobre a obra de Hipólito da Costa, seu pensamento e sua vida. Mecenas Dourado e Carlos Rizzini, após longas pesquisas na Inglaterra e Portugal, conseguiram compor estudos relevantes sobre o jornalista. Outros pesquisadores e estudiosos da história brasileira, no ramo da economia, história social, literatura e educacional também produzem análises sobre as suas ideias com o objetivo de compreender não somente a importância que tiveram a independência do Brasil, mas também os aspectos educativos que as permearam e a capacidade de instruir no sentido de difundir e formar a consciência sobre as condições fundamentais à construção de uma nação prodigiosa material e socialmente.

5. O Correio Braziliense estava proibido de circular na metrópole e nas colônias portuguesas por ser um divulgador das ideias liberais e um inimigo contumaz da aristocracia, advogando pela extinção dos cargos mais importantes do governo monárquico, além de escrever visando influir a favor das reformas políticas e sociais fundamentais ao desenvolvimento material. Entrava no Brasil por meio de contrabando.

Recebido em dezembro-13

Aprovado em janeiro-14 